Kelly E. Matthews, UNIVERSITY OF QUEENSLAND, k.matthews1@uq.edu.au

Aysha Divan, UNIVERSITY OF LEEDS, a.divan@leeds.ac.uk

Nicole John-Thomas, UNIVERSITY OF THE WEST INDIES, nicole.john@sta.uwi.edu Valerie Lopes, SENECA COLLEGE, valerie.lopes@senecacollege.ca Lynn O. Ludwig, UNIVERSITY OF WISCONSIN-STEVENS POINT, lludwig@uwsp.edu Tanya S. Martini, BROCK UNIVERSITY, tmartini@brocku.ca Phillip Motley, ELON UNIVERSITY, pmotley@elon.edu Ana M. Tomljenovic-Berube, MCMASTER UNIVERSITY, tomljeam@mcmaster.ca

\title{
SoTL and Students' Experiences of their Degree- Level Programs: An Empirical Investigation
}

\begin{abstract}
In the global higher education sector, government accountability initiatives are increasingly focused on degree-level competencies that may be expected from university graduates. The purpose of this paper was to examine the extent to which SoTL reflects this increased interest in student learning across the degree program. Articles $(\mathrm{N}=136)$ published in three international SoTL journals, over the past three years, were systematically reviewed using a framework that concentrated on the extent to which they reflected a focus of (a) teaching-emphasis versus learning-emphasis and (b) unit-level (subject, course) versus degree-/ program-level. Our analysis indicated that the majority of SoTL publications $(47 \%)$ were focused at the level of a single unit with an emphasis on teaching practice; in contrast, only a small minority of SoTL publications (9\%) were focused at the level of the overall degree with an emphasis on learning processes. Drawing on our review, we highlight SoTL publications that exemplify the inquiry into student learning at the level of the degree program and offer questions to guide future SoTL inquiries.
\end{abstract}

\section{KEYWORDS}

student experience, curriculum, student learning

The global landscape of higher education is changing rapidly. With greater accountability being demanded of universities by both taxpayers and governments, there has been an increased international emphasis on graduate learning outcomes that are developed during the entire undergraduate degree. To this end, several countries, such as Canada, Australia and the United Kingdom (UK), have put overarching degree-related expectations in place in various ways. In addition to disciplinary content, many of these expectations include the types of transferrable skills (e.g., critical thinking, teamwork, leadership) that employers are increasingly demanding. The United States (USA) is moving in this direction through a voluntary accountability system and the creation of state- 
ments outlining standards for national degree qualifications (see Voluntary System of Accountability Program; Lumina Foundation Degree Qualifications Profile; National Institute for Learning Outcomes Assessment).

This emerging focus on degree program-level student learning presents an important opportunity for the Scholarship of Teaching and Learning (SoTL). SoTL practitioners are in a unique position to make evidence-based claims about the extent to which institutions are meeting the challenges that are inherent in these new priorities for post-secondary education. The question that arises, then, is whether the SoTL literature reflects this new cross-national interest on student learning across degree-level programs.

This paper represents the work of an international writing group with a shared interest in students' experiences of their degree-level programs within the context of SoTL and a common desire to position students' learning across degree programs at the forefront of SoTL. Given that the terminology varies within and across national boundaries, we use unit in reference to a unit of study, course, module or class; academic refers to a member of faculty or teaching staff and program or degree program refers to the complete degree program, or what is called a course in some institutions.

\section{KEY OPERATIONAL DEFINITIONS}

Our effort to examine students' experiences of learning across their entire degreelevel program stands at the intersection of several constructs from the literature on higher education, most notably SoTL, curricula, and learning outcomes. Prior to beginning our investigation, then, it was necessary to define these terms to avoid, as Potter and Kustra (2011) suggest, "the delusion that we all mean the same things just because we are using the same terms" (p. 2).

\section{SoTL}

A plethora of definitions for, and interpretations of, SoTL are available in the literature. Drawing on several of the SoTL founders, a recent article defines SoTL as "the systematic study of teaching and learning, using established or validated criteria of scholarship, to understand how teaching (beliefs, behaviours, attitudes, and values) can maximize learning, and/or develop a more accurate understanding of learning, resulting in products that are publicly shared for critique and use by an appropriate community" (Potter \& Kustra, 2011, p.2). However, we further propound, as others have, that the focus of SoTL should ultimately be on students (beliefs, behaviors, attitudes and values), and the processes by which they learn, as this is often left implicit when scholars are discussing and publishing SoTL (in the US context, see Cerbin, 2013; in the Australian context, see Scoufis, 2013).

\section{Curricula}

Fraser and Bosanquet's (2006) study concerning curricula suggests diverse views ranging from "what is taught in the individual unit or subject, and articulated in the unit outline" (p. 272) to "a collaborative process of learning, with teacher and student acting as co-constructors of knowledge" (p. 275). The latter supports their contention that some academics are "moving away from curriculum as a product provided for students, to a process that enables student learning” (p. 274). Drawing on their work, we define curricula as a spectrum of activities that originates with the decisions involved in determining 
what material should be taught, either in an individual unit or an entire degree program, along with the planned learning experiences that will be created through activities that promote the desired student learning outcomes. While we acknowledge the influence of educational context and disciplinary cultures in relation to curricula (see Becher, 1994; Becher \& Trowler, 2001; Gibbs, 2010), the scope of this article (the place of students' experiences of learning in SoTL inquiry) precludes a more in-depth discussion.

\section{Learning Outcomes}

There is increasing public skepticism in many countries concerning higher education degree qualifications, and the extent to which new graduates are learning the skills that are needed in the current labor market (Yorke \& Knight, 2006). This is evidenced via increasing government accountability policies, tied to funding in some countries, which challenge the sector to articulate the attributes or outcomes of degree programs and provide evidence that students have attained them (with the terms varying by country). Examples of how some countries are defining graduate learning outcomes/attributes include:

Australia: Graduate attributes are the qualities, skills and understandings a university community agrees its students should develop during their time with the institution. These attributes include but go beyond the disciplinary expertise or technical knowledge that has traditionally formed the core of most university degree programs. They are qualities that also prepare graduates as agents of social good in an unknown future (Bowden, Hurt, King, Trigwell \& Watts, 2000, as cited in Barrie, 2006).

United Kingdom: A set of achievements - skills, understandings and personal attributes - that make graduates more likely to gain employment and be successful in their chosen occupations, which benefits themselves, the workforce, the community and the economy (Yorke \& Knight, 2006).

United States: Learning outcome statements ... identify what the student should be able to demonstrate, represent, or produce because of what and how they have learned at the institution or in a program. That is, they translate learning into actions, behaviors, and other texts from which observers can draw inference about the depth and breadth of student learning (Maki, 2010).

\section{CURRICULA, LEARNING OUTCOMES AND SOTL: STUDENTS' EXPERIENCES AT THE DEGREE LEVEL}

An examination of SoTL literature related to learning outcomes suggests two potentially important gaps. First, students' voices appear to be neglected relative to those of academics, and their learning processes receive much less attention than learning endpoints (i.e., questions about whether a teaching intervention was successful). Second, there appears to be a preponderance of literature that is situated within the boundaries of a single unit at the expense of studies that speak to students' experiences of the full degree program. Each of these will be discussed in turn.

Student perceptions of learning. Levin (2000) acknowledges that, while students are the intended beneficiaries of curricular reform designed to improve learning outcomes, elementary and secondary students' perspectives are often neglected. The same appears to be true of higher education generally, and SoTL literature more specifically, with stu- 


\section{Curriculum planned within disciplinary cultures of Higher Education}

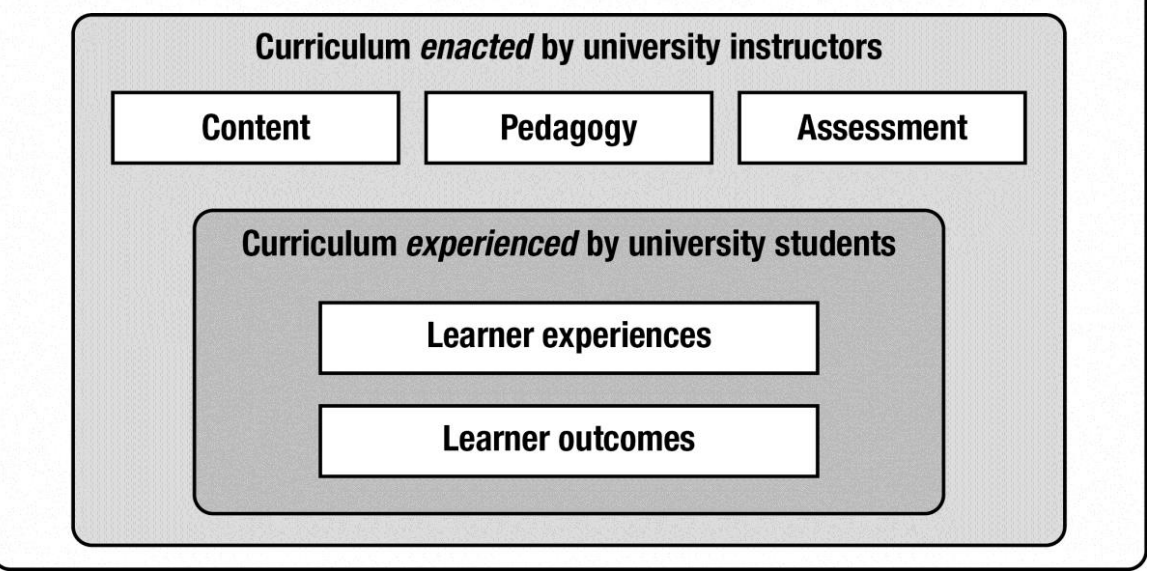

Figure 1. Visual construct to situate students within curriculum (updated from Matthews, 2010)

dents' views often being neglected relative to those of academics. This underrepresentation of the student voice makes it difficult to improve curricula or to "say with any certainty whether students have learned what academics are teaching" (Association of American Colleges \& Universities, 2002, p. 18). The lack of students' perspectives in the SoTL literature is noteworthy, given that such research has a long, rich history in the Higher Education literature that predates SoTL. For example, the well-established student-centered and teacher-centered constructs arose from qualitative research drawing on the student perspective as a means to understand how teacher practices and learning environments influenced students' experiences and approaches to learning (i.e., deep versus surface) (Biggs \& Tang, 2007; Ramsden, 1992; Saljo, 1979).

Beyond documenting what students have learned, it is also important to examine how and why learning occurred, as these can inform teachers' pedagogical practices.

Students are the obvious source of information for understanding learning processes; indeed, Erickson and Schultz (1992) remind us of students' unique abilities to provide information about the relationship between the enacted and experienced curriculum (see Figure 1). As Cerbin (2013) notes, however, SoTL often leans toward "what works" inquiries with an emphasis on assessing teaching methods or the results of learning rather than illuminating how students get to that "endpoint" or their insights into learning processes.

Degree-level learning. Concerns about the lack of a student voice in the SoTL literature are particularly relevant with regard to student acquisition of transferable skills and graduate learning outcomes, which tend to develop across the curriculum rather than within the boundaries of a single unit (Yorke \& Knight, 2006). As accountability agendas increasingly influence the higher education sector, many are calling for SoTL to play a role at the institutional level (Hutchings, Huber, \& Ciccone, 2011; Hutchings et al., 2013). However, the assessment and evaluation (quality assurance or accreditation) activities of institutions rarely enhance teaching activities or curricula design, nor do 
they enable students' development of degree program learning outcomes (Ewan, 2009; Kuh \& Ewell, 2010). One reason for this disconnect between SoTL practitioners and institutional assessment and evaluation regimes may be that SoTL is focused on unit-level curricular innovations rather than inquiry at the level of the degree program curricula (Hubball, Pearson, \& Clarke, 2013).

To summarize, then, there appear to be two important gaps in the SoTL literature related to learning outcomes. First, there are suggestions that SoTL is neglecting the "L" and overlooking students' insights into their learning processes (Cerbin, 2013). Second, there are arguments that SoTL needs to expand from the narrow focus on unit-level teaching innovations to the broader level of the degree program curricula (Hubball et al., 2013).

\section{SYSTEMATICALLY REVIEWING THE LITERATURE: THE FOCUS OF SOTL}

Guided by a conceptual literature review recently published by Amundsen and Wilson (2012), we elected to carry out a systematic examination of recent SoTL publications to test the hypothesis that students' perspectives of their degree-level experiences were lacking in the SoTL literature. We did so on the basis that scholarly outputs offer insight into what is valued by an academic community, and the peer-review process affords some sense of quality control. Though it is a relatively new community, SoTL does have an emerging history that can be explored via a systematic literature review of its peer-reviewed journals.

We formulated three questions to guide the literature review:

1. To what extent is SoTL focused on students' experiences of learning versus teachers' classroom practices?

2. To what extent is SoTL focused on teaching and learning at the unit level versus the degree program level?

3. To what extent is SoTL capturing students' experiences of learning across the degree program?

\section{Selecting Articles for the Literature Review}

In selecting journals for our analysis, we focused for two reasons on those that explicitly identified SoTL in their title or aims. First, we view SoTL as distinctly identifiable within the Higher Education community. Second, our intent was to explore SoTL and self-identified SoTL journals were deemed as clearly being affiliated with the movement. We also made an effort to include publications that were likely to attract the work of international authors, as SoTL is represented as an international community. The selected journals were the International Journal for the Scholarship of Teaching and Learning, the International Journal of Teaching and Learning in Higher Education, and the Canadian Journal for the Scholarship of Teaching and Learning. Given our interest in assessing the current state of the literature, we opted to restrict our review to articles published between 2010 and 2012. Finally, we limited our analysis to empirical articles (rather than invited papers or theoretical essays), as our goal was to provide a window into the type of scholarly activities currently being carried out and favorably peer-reviewed by SoTL scholars. These empirical articles employed quantitative and qualitative methods.

Among the empirical articles, we excluded those studies whose sole focus was (a) testing or validating an instrument for research (e.g., a survey), (b) testing a specific re- 
search methodology, (c) examining the relations between psychological variables without a substantive connection to teaching and learning (e.g., the relationship between personality variables and study habits), or (d) studying teaching and learning outside of higher education institutions (e.g., primary or secondary schools).

Altogether, 154 empirical articles were available for inclusion in the review. Seventeen papers were omitted based on the exclusion criteria noted above; one additional article was excluded because it was published in a language other than English. Thus, a total of 136 articles were included in our literature analysis.

\section{Selecting an Analytic Framework}

Inspired by the work of Healey (2005), we considered our dual foci (teaching-emphasis versus learning-emphasis and unit-level versus program-level) as orthogonal dimensions, resulting in a $2 \times 2$ framework that was used to guide our analysis (see Figure 2).

Focus 1: Teaching-emphasis versus learning-emphasis. Cerbin (2013) distinguishes teaching from learning in the context of SoTL as "assessment of teaching methods" to determine the pedagogical effectiveness (the " $T$ " in SoTL) from the "exploration of paths that students take to get the outcome" (the "L" in SoTL). Essentially, Cerbin is distinguishing the process (how students learn) from the product (what students learned), but acknowledges the complex interplay of the " $T$ " and the "L." Our contention is that the process (how students learn) and the product (what students learn) should be overlapping in SoTL inquiry and that students' insights can shed light on the interdependency of learning and teaching.

However, given the aforementioned suggestions that SoTL is often focused on teaching and "what works" inquiry, we conceptualized two categories. To address the issue of whether SoTL inquiry focuses on teaching or learning, we classified SoTL publications as having either "teaching-emphasis" or "learning-emphasis." While we considered these two foci along a single spectrum (Kember, 1997), our categorization highlights that "learning-emphasis" encompasses the dynamic interplay of students' learning processes with the activities of teachers, while "teaching-emphasis" neglects the learners' processes or pathway toward achieving learning, instead focusing on the product or outcome. We use the following classification criteria:

Teaching-emphasis. Papers that provided insight into teaching methods (i.e., assessment or evaluation of the product of teaching innovations) were categorized as "teachingemphasis." Two questions were used to guide classification: Do these SoTL findings offer insight into teaching practices or behaviors? Is this paper about evaluation or judging the effectiveness of a teaching intervention?

Learning-emphasis. Papers that provided insight into student learning (i.e., had a focus on understanding what students do to achieve learning) were classified as "learningemphasis." In particular, we were guided by the following two questions: Do these SoTL findings offer insight into how students are learning, the process of learning, or the students' learning experiences? Do these SoTL findings offer reflective insights into teaching practices and how they influence student learning or offer insights into the relationship between teaching and learning?

Focus 2: Unit-level versus program-level. An additional guiding question for our analysis was whether SoTL focused on the level of the unit or of the degree-program. 
unit-level

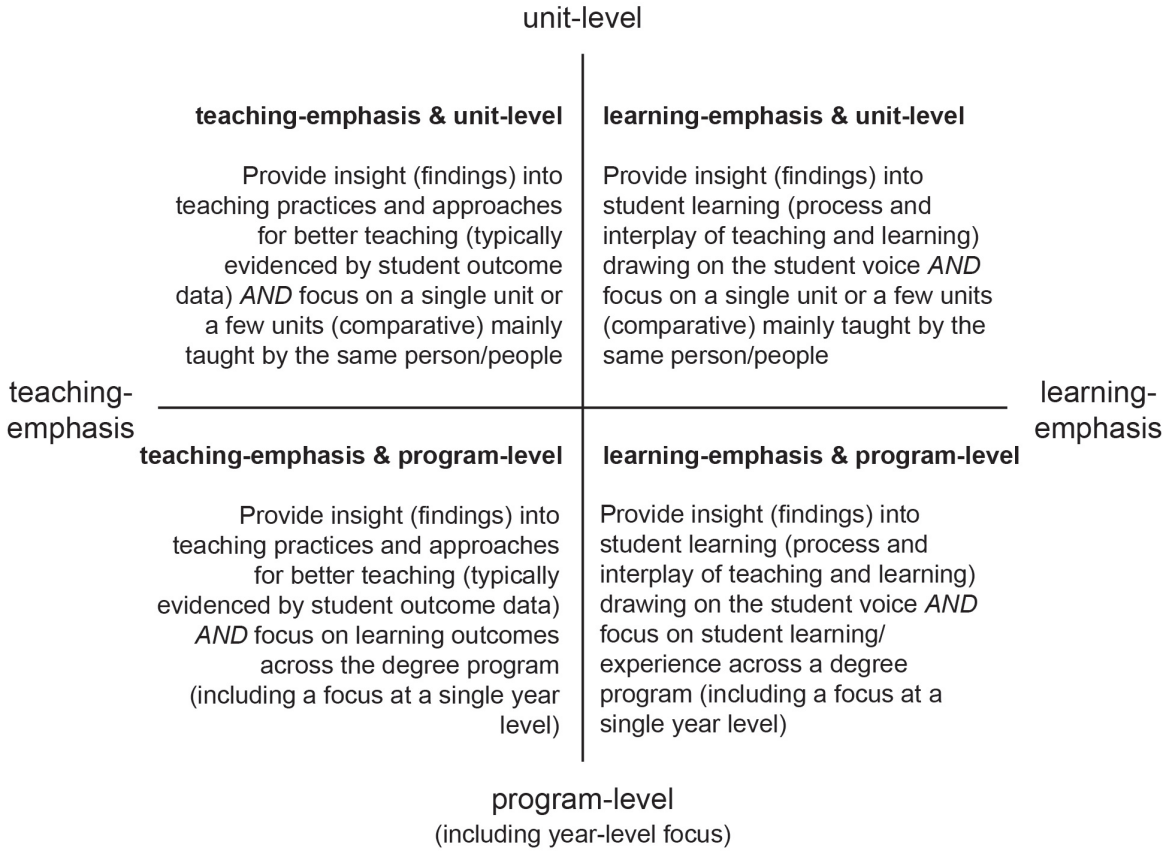

Figure 2. Framework for conceptualizing unit-level versus program-level (y axis) and teaching-emphasis versus learningemphasis ( $x$ axis) foci used to classify articles.

Specifically, we classified publications as either "unit-level” or "program-level” using the following criteria:

Unit-level. These papers reported on scholarship that was focused on a single unit or a few units (for comparative purposes) that were mainly taught by the same person/ people. The focus was on unit-level learning objectives.

Program-level. Papers classified as program-level reported on scholarship that related to broader program-level learning outcomes (e.g., multiple units across one or more years within the same major or degree program).

\section{Reviewers and the Analysis Process}

Each author of this paper reviewed 19 articles using an online form. The following information about each article was recorded: identifying information (e.g., title, journal, volume, issue, authors), country of first author, single or multi-institutional data collection, methodological approach (i.e., qualitative, quantitative, or mixed methods), teaching- or learning-emphasis focus, and unit- or program-level focus. Open text boxes allowed each reviewer to add notes and to indicate whether they wanted the moderator (Matthews) to reassess their analysis.

Consistency in coding across authors was ensured via a two-stage reliability check before the reviewing period. The first stage was conducted as a group, and the second was completed independently. During this two stage process, refinements were made to the criteria to ensure consistency in coding, and the online form was amended accord- 
ingly. After all reviewers had submitted their data, the moderator reassessed 22 articles that had been flagged by reviewers.

\section{Findings from the Literature Review}

The first author of the majority of papers was from the USA (53.7\%) followed by Canada (19.1\%), and Australia (10.3\%). Papers from the UK (3.7\%) were fewer in number; several other countries (e.g., Sweden, Israel, New Zealand, Turkey) had only one or two listed as the first author of their publications, in the selected journals. Overwhelmingly, authors reported on scholarly endeavors that took place within a single institution (91\%). Publications were fairly evenly divided across qualitative (38.6\%), quantitative (34.6\%), and mixed (28.7\%) methodologies.

Focus 1: Learning-emphasis versus teaching-emphasis. The majority of articles (67\%) were classified as reflecting a teaching-emphasis. These articles tended to focus on a teaching intervention conducted by the authors/teachers that drew on student data sources of outcome (e.g., surveys, grades, assessment artifacts) to indicate the success of the intervention. Many of these articles were explicitly an "evaluation" which, by definition, refers to a judgment being made on the effectiveness of an intervention, without considering the student learning process that rendered it effective. Papers classified as having a learning-emphasis $(33 \%)$ drew heavily on the student voice and the student experience of learning. Data were typically sourced from students via focus groups and interviews, with some articles drawing on reflective writing and student essays. Articles that discussed the interactions between teachers' pedagogies and their influence on students' learning processes were classified as having a learning-emphasis.

Focus 2: Unit-level versus program-level. The majority of the articles (71\%) were focused on scholarship related to individual units. The remaining $29 \%$ of the articles were

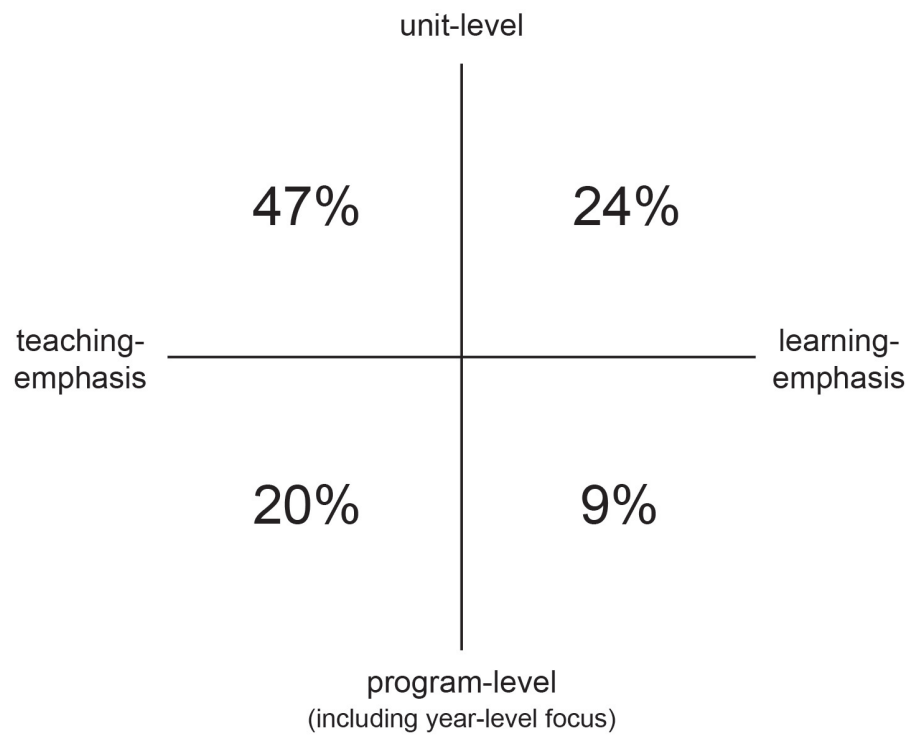

Figure 3. Overview of findings (analysis of 136 SoTL articles) categorized within a framework that conceptualized articles as being unit-level versus program-level ( $y$ axis) and teaching-emphasis versus learning-emphasis ( $x$ axis). 
program-focused. Approximately half of these program-focused articles examined postgraduate programs, with several aimed at exploring the learning experiences of underrepresented student cohorts. A further $9 \%$ of the program-focused studies examined a single year (e.g., the first-year experience or transition into tertiary studies).

Applying the framework. After applying the findings to our framework (see Figure 3 ), it became clear that approximately half of the articles in our literature review fell into the teaching-emphasis/unit-level category. Articles that provided insight into students' experiences of learning (i.e., learning-emphasis) at the program-level were not well represented (only 9\%) in the SoTL articles reviewed for this study.

Of the few SoTL articles found to be oriented toward learning-emphasis at the program-level, we have selected a few exemplary publications as potential models to guide future SoTL research. The chosen examples highlight qualitative and quantitative approaches that meaningfully capture the student perspective and highlight broader implications that can inform curricular reform efforts and individual pedagogical teaching practices. Interestingly, we found no exemplary mixed methods studies that were learning-emphasis at the program-level; therefore, we offer this as a rich potential area of future SoTL inquiry.

\section{Exemplars of Learning-emphasis/Program-level SoTL Publications}

Reid, Taylor and Petocz (2011) draw on student interviews from across the degree program to explore students' perspectives of ethics in a business program at a metropolitan Australian university. They employ phenomenology as a methodology and discuss the results in terms of an established theory of ethical thinking. Importantly, the authors draw three broad, but practical, pedagogical implications to facilitate student learning and thinking, regarding ethics.

Grawe (2011) explores the extent to which assessment activities across disciplines require quantitative reasoning, drawing on qualitative data from student portfolios at a US liberal arts college. Students' writings offer rich insights into their perspectives about the extent to which a specific learning outcome (quantitative reasoning) is incorporated into the undergraduate curricula.

Sampson and Comer (2012) inquired into post-graduate students' beliefs about relevant learning outcomes and skills acquisition in an engineering program in New Zealand. Interviews allowed students to express the outcomes and skills that were relevant to them and how such skills/outcomes were developed. The article highlights how insights into students' thoughts about relevant learning outcomes can inform program development.

Tuitt (2010) explored the student voice of black female students in an elite, predominantly Caucasian post-graduate program in the USA. In-depth interviews were thematically analyzed within a theoretical framework and revealed seven pedagogical practices that students felt were effective in enhancing their visibility in the learning environment.

Finally, Yang, Webster and Prosser (2011) explored the learning experiences of firstyear students across multiple disciplines at a Hong Kong university to ascertain the level of students' inductions into their discipline with respect to knowledge, research, and skills, as well as students' abilities to integrate learning across their units. Using both phenomenography and content analysis, the authors analyzed information gathered from focus group interviews to establish a set of hierarchical "outcome spaces." 


\section{IMPLICATIONS OF ANALYSIS FOR SOTL}

SoTL has its origins in the Scholarship of Teaching thanks largely to Ernest Boyer (1990), who argued that teaching is central to academic practice. While the notion has expanded and evolved (as evidenced by the incorporation of the word Learning), the original focus of SoTL was on teaching and teachers' practices as the means of highlighting the importance of teaching within a sector that emphasized research. As a result, SoTL is often criticized for emphasizing "show and tell" pieces for instructors that lack theory (Hutchings, 2007). Though our analysis did not explore theory, it did suggest that published SoTL articles are predominantly reporting on teachers exploring their own classroom practices.

Suggestions for making students more prominent in SoTL have included students as collaborators in SoTL projects (Werder \& Otis, 2010; Felten et al., 2013), students as change agents (Healey, Cook-Sather, Gerum \& Yanagida, 2012), and students as primary audiences for disseminating SoTL outcomes (McKinney, 2012). However, McKinney also urges authors in SoTL to go beyond simply documenting the learning intervention and outcome, arguing for greater recognition of the student voice and more evidence that sheds light on what students think of their learning. In keeping with this idea, our analysis revealed a surfeit of SoTL publications that described teaching practices without offering insight into students' experiences of learning, lending credence to McKinney's argument.

The need for additional evidence concerning students' experiences across the degree is particularly important in the context of curricular reform that is designed to address international government accountability initiatives. However, our analysis of SoTL publications strongly supported the claim made by Hubball, Pearson and Clarke (2013) that "the [SoTL] emphasis has primarily been on individual pedagogical practices in the classroom" with far less scholarship dedicated to the "program-level educational reforms that are occurring in universities around the world” (p. 42). In 2003, Tagg argued for a collective and integrated approach to curriculum design, suggesting that isolated studentcentered units in curricula dominated by teacher-centered units are ineffective. To address this, Barnett and Coate (2005) argue for greater engagement with curricula in higher education, proposing a new domain-the Scholarship of Curriculum. Such an endeavor would certainly present challenges. For example, Yorke and Knight (2006) highlight the complexity of designing and developing curricula to achieve complex student learning outcomes. However, Hubball, et al. (2013) suggest a way forward by building on the Scholarship of Curriculum Practice (SoCP) model (Hubball \& Gold, 2007). They offer a conceptual framework for curricula inquiry, acknowledging the role of leadership in such endeavors and provide examples of how SoCP can operate within universities. Strategies to embed SoTL into institutional cultures are discussed by Williams et al. (2013). A further hurdle resides in finding meaningful ways to assess learning outcomes, particularly in the light of government accountability agendas.

While these challenges are not trivial, we believe that students are uniquely positioned to assist academics in meeting them. Beyond their academic performance via unit grades and cumulative grade point averages, students can offer insight into the enacted and experienced curricula and the processes by which degree-level learning outcomes (e.g., critical thinking, quantitative skills and ethical reasoning) are achieved. Unfortu- 
nately, our study reveals that SoTL publications are generally failing to capture students' insights and unique perspectives of graduate learning outcomes across curricula. If SoTL is to evolve and increase its relevancy in the changing higher education landscape, then we believe its focus must shift.

While many others have suggested this shift is needed (Cerbin, 2013; Hutchings et al., 2011; Hubball et al., 2013; Scoufis, 2013), our study offers empirical evidence of gaps in the SoTL literature. The heuristic tool we developed (Figure 2) allows for practitioners to reflect on the focus of their SoTL practices and publications; offers institutions a framework to focus their SoTL efforts more strategically; and, invites the SoTL community to debate what distribution is appropriate across the four categories.

\section{LIMITATIONS}

We acknowledge that a more comprehensive analysis would have been achieved with a review of additional publication outlets. There are numerous journals with long-standing histories in the field of Higher Education. However, we had to place pragmatic boundaries around the scope of the literature review and our aim was to investigate those journals explicitly dedicated to publishing in the emerging sub-field of SoTL. We also acknowledge that other approaches to reviewing the literature could have legitimately been selected (e.g., examining the publications of SoTL founders or searching journals broadly, using the keyword SoTL). Additional systematic inquiries of SoTL literature would be beneficial.

Further, while we aspired to select international SoTL journals, our search continually led us back to North American journals. Indeed, approximately one-third of the articles meeting our selection criteria listed a North American as the first author. This suggests that (1) many people writing about SoTL outside of North America are likely publishing in other (non-SoTL explicit) education journals and (2) our conclusions may primarily be based on North American SoTL practices. How teaching and learning inquiries are conducted, and what SoTL might be called, outside of North American countries warrants further investigation.

\section{SOTL AND STUDENT LEARNING IN THE DEGREE PROGRAM: FUTURE QUESTIONS}

We conclude by offering several questions to drive future SoTL inquiries of curricula that would draw on students' perspectives at the level of the degree program (see Hubball et al. (2013) for further degree program level questions). During the 2012 ISSOTL conference writing group workshop, we were able to pose a question to other workshop participants: What would you like to know about students' learning across their degree programs? From their responses, and our review of the literature, the following SoTL-situated questions emerged:

- To what extent are students aware of broader degree-level learning outcomes? How can we ensure that degree-level learning outcomes are met?

-What tools foster students' abilities to articulate learning outcomes at the institutional, department and unit levels? How can students best communicate learning gains and skills development resulting from both curricular and co-curricular activities? 
- In what ways are students (and academics) integrating learning across units to achieve broader graduate learning outcomes? What methods/activities can be used to effectively foster deeper reflection and integrative learning across the degreelevel program? How do these differ across degree programs?

As we seek to understand students' experiences of their degree-level programs, these questions make clear that it will be important to explore the integration of student learning across the formal and informal curriculum, as well as learning experiences across units. Also critical are the identification of methods and activities to foster integrative and deep learning and finding effective ways to track and measure the changes that result from learning across programs of study.

\section{CONCLUSION}

The potential value of the scholarship of teaching and learning lies, in large part, in the scope of its invitation to participate.

(Poole, Taylor, \& Thompson, 2007).

As more academics accept the SoTL invitation, the field has the potential to expand beyond enhancing what is known about unit-specific teaching practices to include a collective academic inquiry that genuinely reflects students' perceptions of their learning across the entire degree program. We believe that a move in this direction would represent a productive shift for the field, as it would provide much-needed evidence to inform curricular review processes, as well as make an important contribution to broader social and political discussions about the value of university degree programs.

\section{ACKNOWLEDGEMENTS}

We would like to thank Mick Healey, Beth Marquis and (the late) Sue Vajoczki for their tremendous and effective efforts in organizing and facilitating the writing groups. We also thank the reviewers who provided insightful feedback.

Kelly E. Matthews is a lecturer in Higher Education at the Teaching and Educational Development Institute, University of Queensland, Australia.

Aysha Divan is an Associate Professor in Molecular and Cellular Biology, University of Leeds, UK.

Nicole John-Thomas is a Lecturer in the Department of Chemistry, University of the West Indies.

Valerie Lopes teaches in the Faculty Development Program, Centre for Academic Excellence, Seneca College, Toronto, Canada.

Lynn O. Ludwig is an Assistant Professor of English, University of Wisconsin-Stevens Point, USA.

Tanya Martini is a Professor of Psychology, Brock University, Ontario, Canada.

Phillip Motley is an Assistant Professor in the Department of Communications, Elon University, North Carolina, USA.

Ana M. Tomljenovic-Berube is a recent Ph.D. graduate from McMaster University, Canada, where she studied infectious diseases. 


\section{REFERENCES}

Amundsen, C., \& Wilson, M. (2012). Are we asking the right questions?: A conceptual review of the educational development literature in higher education. Review of Educational Research, 82(1), 90-126.

Association of American Colleges and Universities (AAC\&U). (2002). Greater expectations: A new vision for learning as a nation goes to college. Washington, DC: AAC\&U.

Barnett, R., \& Coate, K. (2005). Engaging the curriculum in higher education. Maidenhead, England: Open University Press.

Barrie, S. C. (2006). Understanding what we mean by the generic attributes of graduates. Higher Education: The International Journal of Higher Education Research, 51(2), 215-241.

Becher, T. (1994). Quality assurance and disciplinary differences. Australian Universities' Review, 37(1), 4-7.

Becher, T., \& Trowler, P. R. (2001). Academic tribes and territories: Intellectual enquiry and the cultures of disciplines (2nd ed.). Buckingham: Society for Research into Higher Education \& Open University Press.

Biggs, J., \& Tang, C. (2007). Teaching for quality learning at university (3rd ed.). Birkshire: McGraw Hill, Society for Research into Higher Education \& Open University Press.

Boyer, E. L. (1990). Scholarship reconsidered: Priorities of the professoriate. Princeton, NJ: The Carnegie Foundation for the Advancement of Teaching.

Cerbin, B. (2013). Emphasizing Learning in the scholarship of teaching and learning. International Journal for the Scholarship of Teaching and Learning, $7(1)$. Retrieved from http://academics.georgiasouthern.edu/ijsotl/v7n1/invited_essays/PDFs/IE_Cerbin.pdf

Erickson, F., \& Shultz, J. (1992). Students' experience of the curriculum. In P. W. Jackson (Ed.), Handbook of research on curriculum (pp. 465-485). New York, NY: MacMillan.

Ewan, C. E. (2009). Learning and teaching in Australian universities: A thematic analysis of cycle 1 AUQA audits. Australian Universities Quality Agency and the Australian Learning and Teaching Council. Retrieved from http://www.olt.gov.au/resources/3899?text=AUQA\& solrsort=score\%20desc

Felten, P., Bagg, J., Bumbry, M., Hill, J., Hornsby, K., Pratt, M., \& Weller, S. (2013). A call for expanding inclusive student engagement in SoTL. Teaching \& Learning Inquiry: The ISSOTL Journal, 1(2).

Fraser, S. P., \& Bosanquet, A. M. (2006). The curriculum? That's just a unit outline, isn't it? Studies in Higher Education, 31(3), 269-284.

Gibbs, G. (2010). Dimensions of quality. York: The Higher Education Academy. Retrieved from http://www.heacademy.ac.uk/assets/documents/evidence_informed_practice /Dimensions_of_Quality.pdf

Grawe, N. D. (2011). The potential for teaching quantitative reasoning across the curriculum: Empirical evidence. International Journal for the Scholarship of Teaching and Learning, 5(1). Retrieved from http://academics.georgiasouthern.edu/ijsotl/v5n1/articles/PDFs /_Grawe.pdf 
Healey, M. (2005). Linking research and teaching: Disciplinary spaces. In R. Barnett (Ed.), Reshaping the university: new relationships between research, scholarship and teaching (pp. 30-42). Maidenhead, England: McGraw-Hill/Open University Press.

Healey, M., Cook-Sather, A., Gerum, N, \& Yanagida, K. (2012, October). Students as change agents, Keynote Presentation to ISSOTL Annual Conference, Hamilton, ON, Canada. Retrieved from http://issotl12.com/plenary-presenters/

Hubball, H. T., \& Gold, N. (2007). The scholarship of curriculum practice and undergraduate program reform: Integrating theory into practice. New Directions for Teaching and Learning, 112, 5-14.

Hubball, H.T., Pearson, M., \& Clarke, A. (2013). SoTL inquiry in broader curricula and institutional contexts: Theoretical underpinnings and emerging trends. Teaching \& Learning Inquiry: The ISSOTL Journal, 1(1), 41-57.

Hutchings, P. (2007). Theory: The elephant in the scholarship of teaching and learning room. International Journal for the Scholarship of Teaching and Learning, 1(1).

Hutchings, P., Borin, P., Keesing-Styles, L., Martin, L., Michael, R., Scharff, L., Simkins, S., \& Ismail. A. (2013). The scholarship of teaching and learning in the age of accountability: Building bridges. Teaching \& Learning Inquiry: The ISSOTL Journal, 1(2).

Hutchings, P., Huber, M. T., \& Ciccone, A. (2011). The scholarship of teaching and learning reconsidered: Institutional integration and impact. San Francisco: Jossey-Bass.

Kember, D. (1997). A reconceptualisation of the research into university academics' conceptions of teaching. Learning and Instruction, 7(3), 255-75.

Kuh, G. D., \& Ewell, P. T. (2010). The state of learning outcomes assessment in the United States. Higher Education Management and Policy, 22(1), 1-20.

Levin, B. (2000). Putting students at the centre in education reform. Journal of Educational Change, 1, 155-172.

Lumina Foundation Degree Qualifications Profile (LFDQP). (2011). Indianapolis, IN: Lumina Foundation. Retrieved from http://www.luminafoundation.org/publications/The _Degree_Qualifications_Profile.pdf

Maki, P. L. (2010). Assessing for learning: Building a sustainable commitment across the institution (2nd ed.). Sterling, VA: Stylus.

Matthews, K. E. (2010). The hidden experience: Mathematics in science. Paper presented at the First International Conference of STEM in Education, Brisbane, Australia. Retrieved from http://stem.ed.qut.edu.au/index.php/conference-proceedings.html\#h

McKinney, K. (2012). Increasing the impact of SoTL: Two sometimes neglected opportunities. International Journal for the Scholarship of Teaching and Learning, 6(1). Retrieved from http://academics.georgiasouthern.edu/ijsotl/v6n1/invited_essays/PDFs/IE_McKinney.pdf

National Institute for Learning Outcomes Assessment (NILOA). (2012). Champaign, IL: NILOA. Retrieved from www.learningoutcomeassessment.org/DQPCorner.html

Poole, G., Taylor, L., \& Thompson, J. (2007). Using the scholarship of teaching and learning at disciplinary, national and institutional levels to strategically improve the quality of postsecondary education. International Journal for the Scholarship of Teaching and Learning, 
1(2). Retrieved from http://academics.georgiasouthern.edu/ijsotl/v1n2/invited_essays /poole/Invited_EssaE_Poole-Taylor-Thompson.pdf

Potter, M. K., \& Kustra, E. (2011). The relationship between scholarly teaching and SoTL: Models, distinctions, and clarifications. International Journal for the Scholarship of Teaching and Learning, 5(1). Retrieved from http://academics.georgiasouthern.edu/ijsotl/v5n1 /essays_about_sotl/PDFs/_PotterKustra.pdf

Ramsden, P. (1992). Learning to teach in higher education. New York, NY: Routledge.

Reid, A., Taylor, P., \& Petocz, P. (2011). Business as usual: Business students' conceptions of ethics. International Journal for the Scholarship of Teaching and Learning, 5(1). Retrieved from http://academics.georgiasouthern.edu/ijsotl/v5n1/articles/PDFs/_ReidTaylorPetocz.pdf

Saljo, R. (1979). Learning in the learner's perspective:Some common-sense conceptions. In Reports from the Institute of Education. University of Gothenburg.

Sampson, K., \& Comer, K. (2011). Engineering research teams: The role of social networks in the formation of research skills for postgraduate students. International Journal for the Scholarship of Teaching and Learning, 5(1). Retrieved from http://academics.georgiasouthern .edu/ijsotl/v5n1/articles/PDFs/_SampsonComer.pdf

Scoufis, M. (2013). Have we lost focus on our students' learning? International Journal for the Scholarship of Teaching and Learning, 7(1). Retrieved from http://academics.georgiasouthern .edu/ijsotl/v7n1/invited_essays/PDFs/IE_Scoufis.pdf

Tagg, J. (2003). The learning paradigm college. Boston, MA: Anker.

Tuitt, F. (2010). Enhancing visibility in graduate education: Black women's perceptions of inclusive pedagogical practices. International Journal of Teaching and Learning in Higher Education, 22(3), 246-257.

Voluntary System of Accountability Program (VSA). (2011). Retrieved from http:// voluntarysystem.org/

Werder, C., \& Otis, M. M. (Eds.). (2010). Engaging student voices in the study of teaching and learning. Sterling, VA: Stylus.

Williams, A.L., Verwood, R., Beery, T.A., Dalton, H., McKinnon, J., Pace, J., Poole, G. and Strickland, K. (2013). The power of social networks: A model for weaving the scholarship of teaching and learning into institutional culture. Teaching \& Learning Inquiry: The ISSOTL Journal, 1(2).

Yang, M., Webster, B., \& Prosser, M. (2011). Exploring the variation in first year undergraduates' induction into their academic disciplines. International Journal for the Scholarship of Teaching and Learning, 5(1). Retrieved from http://academics.georgiasouthern.edu/ijsotl /v5n1/articles/PDFs/_YangWebsterProsser.pdf

Yorke, M., \& Knight, P. T. (2006). Curricula for economic and social gain. Higher Education: The International Journal of Higher Education Research, 51(4), 565-588. 